\title{
Surgical Reconstruction of Ocular Surface Tumors Using Fibrin Sealant Tissue Adhesive
}

\author{
Aline Roseane Queiroz de Paiva ${ }^{a}$ Larissa Abreu de Azevedo Fraga ${ }^{a}$ \\ Virgínia Laura Lucas Torres ${ }^{b}$ \\ ${ }^{a}$ Altino Ventura Foundation, and ${ }^{b}$ Department of Ocular Oncology, Altino Ventura Foundation, Recife, Brazil
}

\section{Key Words}

Biomaterials/fibrin tissue adhesive - Ocular surface tumor .

Anterior segment surgery $\cdot$ Reconstruction surgery

\begin{abstract}
Purpose: To evaluate the surgical outcomes of ocular surface reconstruction in corneal-conjunctival tumors using fibrin tissue adhesive. Methods: A prospective noncomparative study was performed between May 2013 and February 2015. Patients were submitted to routine surgical procedure for corneal-conjunctival tumor excision followed by amniotic membrane graft transplantation using fibrin tissue adhesive (Evicel ${ }^{\circledR}$, Omrix Biopharmaceuticals Ltd., Israel). Results were assessed on the 1st, 7th, 15th and 30th postoperative days to analyze subjective complaints, adhesiveness and positioning of the graft, potential complications and recurrences. Results: Twenty-five eyes were analyzed (male, 14). The diagnosis after the treatment was categorized as squamous cell neoplasia, dysplasia, actinic keratosis, squamous papilloma and compound melanocytic nevus. Few significant symptoms were reported, such as mild hyperemia and ocular dyscomfort. One case developed a conjunctival granuloma which regressed after topical treatment. All grafts were successful with no displacements or retraction
\end{abstract}

postoperatively. There was no clinical recurrence of the tumor in a mean time of follow-up of 11 months. Conclusion: Fibrin tissue adhesive is safe and effective in the surgery of ocular surface tumor. In this series, sutureless amniotic membrane transplantation using fibrin glue has the potential to shorten the surgical time, mitigate inflammation postoperatively and improve patient discomfort.

(c) 2016 S. Karger AG, Base

\section{Introduction}

Ocular surface tumors are those involving the conjunctiva and cornea, the most common being squamous cell carcinoma, dysplasia, papillomas and nevi. Surgical excision biopsy is the gold standard treatment, by excision with a safety margin of approximately $3 \mathrm{~mm}$, which can lead to extensive bare area [1].

One of the main concerns of the surgeons in these cases is to get the best technique for reconstruction of the ocular surface. When wide excisions are necessary for tumor surgery, autologous graft or labial mucosa can be used for surface reconstruction [1]. An alternative is the use of amniotic membrane graft, which has been used in ocular surface reconstruction in surgical scarring diseases

\section{KARGER}

E-Mail karger@karger.com

www.karger.com/oop
(C) 2016 S. Karger AG, Base

2296-4681/16/0024-0207\$39.50/0
Virgínia Laura Lucas Torres

Rua Poeta Zezito Neves, 71, apt 1301

Boa Viagem

Recife, PE 51020-200 (Brazil)

E-Mail virginia.lucas.torres@gmail.com 
of the cornea and conjunctiva [2-8]. The amniotic membrane is the innermost layer of the placenta and is a thick basal membrane with an avascular stroma [1]. The use of amniotic membrane as graft is appropriated due to its anti-inflammatory and anti-scarring effects. Amniotic membrane contains growth factors that promote epithelial wound healing on the surface of the eye, working as a basement membrane substitute or as a temporary graft [2].

Although widely used in ophthalmic surgery, the use of sutures is time-consuming and increases tissue manipulation $[2,3]$. Sutures can cause tissue trauma, potential for granuloma formation and increased surgical time. Postoperatively, it can cause foreign body sensation and its removal is discomfortable. Sutures may increase the chance of infections and when loose or unsecured should be compulsorily removed even when absorbable sutures are used $[3,4]$.

Fibrin glue has been used in amniotic membrane graft and autologous conjunctival transplantation for tissue fixation. This substance is a bioadhesive material which mimics the reactions involved in the coagulation cascade promoting polymerization of fibrinogen by thrombin, which leads to the formation of clot fibrin. Thus, its application is an alternative to sutures $[4,5]$.

The commercially available fibrin adhesives are constituted by two compounds which form a fibrin clot from the mixture of both. The first component is human plasma rich in fibrinogen, diluted in a solution of aprotinin. The second is a solution of thrombin and calcium chloride $[5,6]$.

There is an increasing application of fibrin glue in ocular surgery. Its use has been described for closure of the conjunctiva [3-5], glaucoma surgery [9], trophic ulcer or perforated cornea [10], closure of corneal and scleral tunnel, setting of autologous conjunctiva in pterygium surgery $[3,4,11]$, fixation of amniotic membrane to the sclera and cornea [6], lamellar keratoplasty, limbal transplantation [7] and ocular surface reconstruction, but there are still few reports regarding its use in ocular surface tumor surgeries [5]. This study aims to evaluate the surgical outcomes of surface reconstruction in ocular surface tumors using fibrin sealant tissue adhesive.

\section{Methods}

This is an interventional, prospective, noncomparative study conducted in the Ocular Oncology Department of Altino Ventura Foundation, Recife, Brazil between May 2013 and February 2015. All patients with indication for surgical excision of corneal-con- junctival tumor were enrolled after signing an informed consent form. This study was approved by the Ethics Committee of the institution. Consecutive patients with indication of tumor excision were included either as primary treatment or after neoadjuvant topical chemotherapy failure. The exclusion criteria were patients with very extensive lesions, i.e. more than three quadrants of involvement of the ocular surface that required broad excision, and those with impossibility to comply with the postoperative visits.

After routine ophthalmologic evaluation, patients diagnosed with corneal-conjunctival tumors eligible for surgical treatment underwent excision of conjunctival tumor, followed by cryotherapy and reconstruction with amniotic membrane graft using fibrin glue. Patients were examined at 1, 7, 15 and 30 days postoperatively.

\section{Surgical Technique}

The surgeries were performed by the same surgeon following the routine protocol for each case. Tumor involving cornea and/ or conjunctiva was excised with a surrounding safety margin of approximately $3 \mathrm{~mm}$ in the conjunctiva and approximately $2 \mathrm{~mm}$ in the cornea followed by cryotherapy of the surgical margins. The content of one syringe was applied over the denuded sclera and the content of another syringe was applied over the amniotic membrane graft with the epithelial side facing down. Then, the membrane was flipped up to cover the sclera. Immediately, an iris spatula was used to spread the fibrin glue under the conjunctival edges.

All patients were treated with combined eye drops tobramycin $0.3 \%$ with dexamethasone $0.1 \%$ and artificial tears (sodium carmelose) within 15 days postoperatively. The following aspects were analyzed: subjective complaints, adhesiveness and positioning of the amniotic membrane graft, complications and recurrences.

\section{Results}

Twenty-five eyes from 25 patients were included, 14 of which were male and 11 female. The excised lesions were categorized according to the histological result as squamous cell neoplasia (14), dysplasia (4), actinic keratosis (2), squamous papilloma (1) and compound melanocytic nevus (2). In two cases, the histopathology result was negative for neoplastic cells (pterygium). Such cases were diagnosed clinically as having conjunctival dysplasia and they were treated with neoadjuvant chemotherapy. Presumably, this was the reason the sample was negative for malignant cells. Table 1 summarizes the clinical and histological data of the patients, and figure 1 shows the preand postoperative appearance of 3 patients.

Good adhesion of the amniotic membrane graft was obtained in all cases without dehiscence or graft loss. Conjunctival hyperemia was detected in all cases within the first week postoperatively. One patient presented a pinkish mass diagnosed clinically as pyogenic granuloma in a small area covered by the amniotic membrane graft, which healed after 15 days of topical steroids. Most common symptoms reported were burning and/or ocular dis- 
Table 1. Clinical aspects and histological results of the patients with ocular surface tumors

\begin{tabular}{rllll}
\hline $\begin{array}{l}\text { Patient } \\
\text { No. }\end{array}$ & $\begin{array}{l}\text { Age, } \\
\text { years }\end{array}$ & Gender & Eye & Biopsy results \\
\hline 1 & 61 & M & OS & Squamous cell carcinoma \\
2 & 50 & M & OS & Squamous cell carcinoma \\
3 & 73 & F & OS & Squamous papilloma \\
4 & 71 & F & OS & dysplasia \\
5 & 70 & F & OS & Squamous cell carcinoma \\
6 & 67 & M & OD & Absence of neoplasia (pterygium) \\
7 & 47 & F & OD & Absence of neoplasia (pterygium) \\
8 & 24 & M & OS & Dysplasia + pterigyum \\
9 & 31 & M & OS & Squamous cell carcinoma \\
10 & 78 & F & OD & Squamous cell carcinoma \\
11 & 65 & F & OS & Compound melanocytic nevus \\
12 & 37 & M & OD & Squamous cell carcinoma \\
13 & 18 & M & OD & Squamous cell carcinoma \\
14 & 21 & M & OS & Actinic keratosis \\
15 & 46 & F & OS & Actinic keratosis \\
16 & 75 & M & OS & Dysplasia \\
17 & 14 & F & OD & Dysplasia \\
18 & 53 & F & OS & Squamous cell carcinoma \\
19 & 63 & M & OS & Squamous cell carcinoma \\
20 & 36 & M & OS & Squamous cell carcinoma \\
21 & 42 & M & OS & Squamous cell carcinoma \\
22 & 54 & F & OS & Squamous cell carcinoma \\
23 & 11 & F & OD & Compound melanocytic nevus \\
24 & 71 & M & OD & Squamous cell carcinoma \\
25 & 65 & M & OS & Squamous cell carcinoma \\
\hline & & & & \\
& & & \\
13 & & &
\end{tabular}

comfort and tearing (3 cases), foreign body sensation (2 patients) and local pain (1 case).

All symptoms were mild and transient, with complete resolution within a period of 7 days postoperatively. Until the 30th postoperative day, all eyes had evolved with good healing of the ocular surface. There was no clinical recurrence of the tumor in a mean time of follow-up of 11 months (range, 8-24 months).

\section{Discussion}

Amniotic membrane transplantation has been used successfully in conjunctival surface reconstruction due to its anti-inflammatory property and minimal scar formation $[7,12,13]$. Fibrin tissue adhesive has been widely applied in various medical fields, including ophthalmic surgery such as vitreoretinal, glaucoma, ocular surface, cataract and refractive surgery $[3-9,13-18]$. To ourknowledge, this is one of a few reports concerning the applicability of bioadhesive in ocular surface tumor surgery $[5,15]$.

Fibrin Sealant Tissue Adhesive in Ocular Surface Tumors

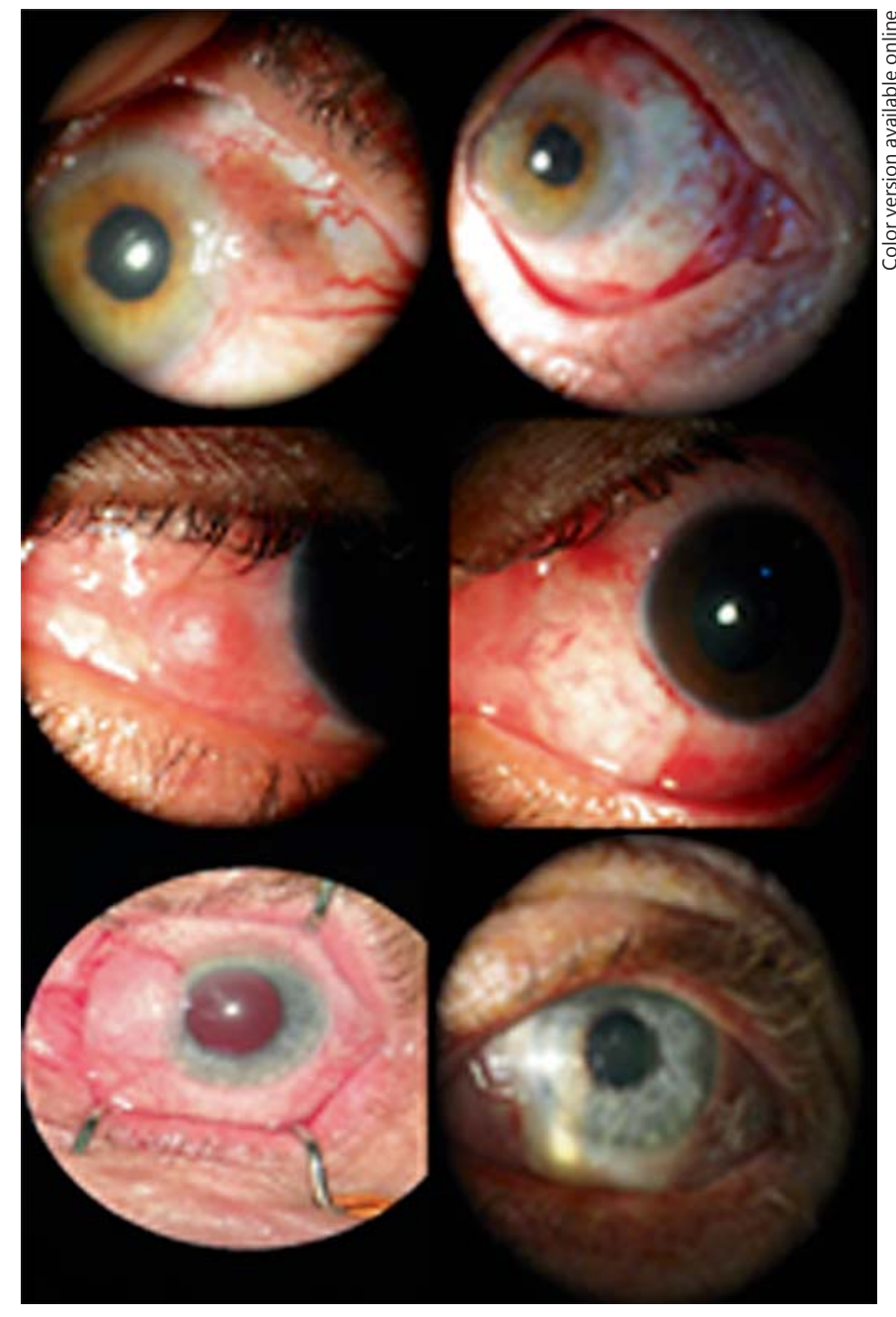

Fig. 1. Pre- and postoperative appearance of 3 patients.

Bioadhesives have the advantage of faster surgical procedure, absence of friction and tension applied to the tissues, uniform adhesion between the handled structures, more comfort, less inflammation and lower risk of tissue necrosis, infections and pyogenic granuloma formation $[4,7,13,17,18]$. However, its application requires speed and skill of the surgeon, due to the rapid precipitation of its components $[4,8,13,18]$. We overcame this aspect by using the two substances separately, thus avoiding premature precipitation and difficulty to handle the graft, since this can happen when we use the two substances at once.

It is supposed that the use of biological adhesives may cause the transmission of some infectious diseases, since it is made from human or bovine fibrin, but there is no scientific evidence so far. However, no report of transmis- 
sion of viruses such as HIV, hepatitis B and C and Creutzfeldt-Jakob disease has been described to date [4].

The good adhesion of amniotic membrane graft in all patients and lack of graft loss in all cases indicates that the fibrin tissue adhesive was a safe and effective option in the reconstruction of the surgical area after excision of ocular surface tumors, and this is in accordance to results found in other studies [19]. A study carried out by Rubin et al. [3] showed no graft loss in two groups comparing adhesive and suture. In their study, complications occurred on the 7th day after surgery, which were a conjunctival granuloma and a retraction of the graft with a subsequent conjunctivalization [3]. In our series, we prevented scleral exposure due to occasional graft retraction pushing the graft under the conjunctival edge.

In a study involving 11 eyes with partial deficiency of limbal stem cells, all eyes maintained a stable and smooth corneal surface without recurrent erosion or persistent epithelial defect and showed less corneal opacity and neovascularization, showing that the use of fibrin tissue adhesive is safe and effective even in these cases [7]. Dal Pizzol et al. [5], in a retrospective, noncomparative study of case series evaluating the use of fibrin glue in a wide range of ophthalmic surgical procedures, found that its use appears to be safe and effective, with low rates of complications in ocular surface surgery, cataracts and glaucoma.

It is supposed that the slighter ocular hyperemia and virtually no foreign body sensation or ocular discomfort found in this study were due to factors such as less tissue manipulation, hemostatic properties inherent to the fibrin tissue adhesive minimizing bleeding during the surgery and suture absence. Similar results were found in other studies $[3-8,11,20]$. The only complication detected was pyogenic granuloma, which was treated with corticosteroid eye drops. Is noteworthy that lower inflammation and ocular discomfort allow earlier return to work, restoring lifestyle and productivity [3].

The study has an analytical approach limited by the lack of a control group, the small number of patients and short follow-up. However, this study will provide the basis for other upcoming studies that could confirm the findings presented here.

\section{Conclusion}

Fibrin sealant tissue adhesive can be used safely and effectively in the surgery of ocular surface tumor. In this series, sutureless amniotic membrane transplantation using fibrin glue has the potential to shorten the surgical time, mitigate inflammation postoperatively and improve patient discomfort.

\section{Statement of Ethics}

The authors are ensuring quality and integrity of this research; the confidentiality and anonymity of our research respondents will be respected. These patients agreed to participate in this study voluntarily and this research is independent and impartial.

\section{Disclosure Statement}

None of the authors has any potential conflicts of interest.

\section{References}

1 Espana EM, Prabhasawat P, Grueterich M, Solomon A, Tseng SCG: Amniotic membrane transplantation for reconstruction after excision of large ocular surface neoplasias. $\mathrm{Br} \mathrm{J}$ Ophthalmol 2002;86:640-645.

2 Carvalho-Rêgo PR, Gomes JA, Ballalai PL, Cunha MC, Sousa LB, Erwenne CM: Amniotic membrane for ocular surface reconstruction after conjunctival squamous cell carcinoma resection (in Portuguese). Arq Bras Oftalmol 2008;71:22-27.

3 Rubin MR, Dantas PE, Nishiwaki-Dantas MC, Felberg S: Efficacy of fibrin tissue adhesive in the attachment of autogenous conjunctival graft on primary pterygium surgery (in Portuguese). Arq Bras Oftalmol 2011;74: 123-126.
4 Coral-Ghanem R, Oliveira RF, Furlanetto E, Ghanem MA, Ghanem VC: Conjunctival autologous transplantation using fibrin glue in primary pterygium (in Portuguese). Arq Bras Oftalmol 2010;73:350-353.

5 Dal Pizzol MM, Roggia MF, Kwitko S, Marinho DR, Rymer S: Use of fibrin glue in ocular surgery (in Portuguese). Arq Bras Oftalmol 2009;72:308-312.

6 Pirouzian A, Ly H, Holz H, Sudesh RS, Chuck RS: Fibrin-glue assisted multilayered amniotic membrane transplantation in surgical management of pediatric corneal limbal dermoid: a novel approach. Graefes Arch Clin Exp Ophthalmol 2011;249:261-265.
7 Keirkhah A, Casas V, Raju VK, Tseng SC: Sutureless amniotic membrane transplantation for partial limbal stem cell deficiency. Am J Ophthalmol 2008;145:787-794.

8 Lee JH, Kang NY: Comparison of fibrin glue and sutures for conjunctival wound closure in strabismus surgery. Korean J Ophthalmol 2011;25:178-184.

9 Kahook MY, Noecker RJ: Fibrin glue-assisted glaucoma drainage device surgery. Br J Ophthalmol 2006;90:1486-1489.

10 Cañones-Zafra R, Benítez-Herreros J, Kubiak K, Montes-Mollón MA, Jiménez-Parras R: Sterile non-traumatic corneal perforation treated with Tachosil ${ }^{\circledR}$ (in Spanish). Arch Soc Esp Oftalmol 2011;86:264-266. 
11 Kim HH, Mun HJ, Park YJ, Lee KW, Shin JP: Conjunctivolimbal autograft using a fibrin adhesive in pterygium surgery. Korean J Ophthalmol 2008;22:147-154.

12 Liu J, Sheha H, Fu Y, Liang L, Tseng SC: Update on amniotic membrane transplantation. Expert Rev Ophthalmol 2010;5:645-661.

13 Kheirkhah A, Casas V, Blanco G, Li W, Hayashida Y, Chen YT, Tseng SC: Amniotic membrane transplantation with fibrin glue for conjunctivochalasis. Am J Ophthalmol 2007;144:311-313.

14 Saha K, Leatherbarrow B: Orbital lymphangiomas: a review of management strategies. Curr Opin Ophthalmol 2012;23:433-438.
15 Hayasaki A, Nakamura H, Hamasaki T, Makino K, Yano S, Morioka M, Kuratsu J: Successful treatment of intraorbital lymphangioma with tissue fibrin glue. Surg Neurol 2009;72:722-724; discussion 724.

16 Kurian A, Reghunadhan I, Nair KG: Autologous blood versus fibrin glue for conjunctival autograft adherence in sutureless pterygium surgery: a randomised controlled trial. $\mathrm{Br} \mathrm{J}$ Ophthalmol 2015;99:464-470.

17 Huerva V, March A, Martinez-Alonso M, Muniesa MJ, Sanchez C: Pterygium surgery by means of conjunctival autograft: long term follow-up. Arq Bras Oftalmol 2012;75:251255.

18 Welder JD, Pandya HK, Nassiri N, Djalilian AR: Conjunctival limbal autograft and allograft transplantation using fibrin glue. Ophthalmic Surg Lasers Imaging 2012;43: 323-327.
19 Asoklis RS, Damijonaityte A, Butkiene L, Makselis A, Petroska D, Pajaujis M, Juodkaite G: Ocular surface reconstruction using amniotic membrane following excision of conjunctival and limbal tumors. Eur J Ophthalmol 2011;21:552-558.

20 Miranda-Rollón MD, Pérez-González LE, Sentieri-Omarrementería A, Martínez-Rodríguez R, Parente-Hernández B, JuncedaMoreno J: Pterygium surgery: comparative study of conjunctival autograft with suture versus fibrin adhesive (in Spanish). Arch Soc Esp Oftalmol 2009;84:179-184. 